\title{
0 agir comunicativo no contexto das práticas de educação em saúde pública: um estudo à luz da teoria da ação comunicativa de J. Habermas
}

\section{The communicative action in the context of education practices in publichealth: a study based on J. Habermas's theory of communicative action}

\author{
Raimunda Nonato da Cruz Oliveira*
}

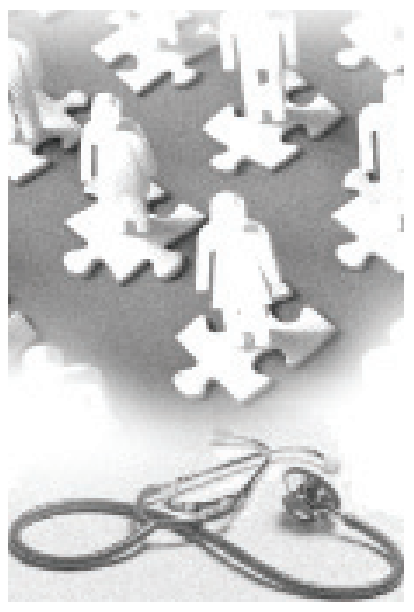

Resumo: O presente estudo traz uma reflexão sobre o agir comunicativo enquanto estratégia de redirecionamento das práticas de saúde pública no Brasil. Este propósito se reveste de fundamental importância, no momento em que se comemoram duas décadas de implantação do Sistema Único de Saúde (SUS) no Brasil. Nesse ínterim, embora tenha sido colocado como o "melhor plano de saúde do mundo", vem enfrentando, em sua operacionalização, dificuldades de ordem técnica e política para sua implementação. A grande questão que se coloca é: como o SUS tem enfrentado os desafios para garantir, junto ao público alvo, a melhoria da qualidade de vida e saúde da população usuária? Muitos são os enfoques a emergirem a partir desse questionamento, porém o nosso foco de estudo terá como recorte a análise das práticas socioeducativas instituídas pelo Ministério da Saúde/Fundação Nacional de Saúde, enfatizando o seu arcabouço teórico-metodológico e as contribuições da teoria do agir comunicativo de J. Habermas.

Palavras-chaves: Educação em saúde. Sistema Único de Saúde. Agir comunicativo. Saúde pública. Qualidade de vida.

* Assistente social formada pela UFPI, educadora em Saúde da Fundação Nacional de Saúde (Funasa/ MS), mestra em Serviço Social pela Pontifícia Universidade Católica de São Paulo. Especialista em Educação em Saúde Pública (USSC/SP) e professora do curso de Serviço Social do Instituto Camillo Filho em Teresina/PI, Brasil. Atualmente é superintendente estadual da Funasa no Piauí. E-mail: Raimunda.oliveira@ funasa.gov.br. 


\begin{abstract}
This study is a reflection on the communicative action as a strategy to redirect public health practices in Brazil. This purpose has a fundamental importance at the moment that the Brazilian Unified Health System (UHS) celebrates its two decades of implantation. Although it is considered the "best health plan in the world", the UHS has faced technical and political difficulties in its implementation. The issue that arises is: how has the UHS faced challenges to ensure its users' quality of life and health? There are a lot of approaches that emerge from that issue, but our focus will be the analysis of the socio-educational practices created by the Ministry of Health/National Health Foundation, and we will emphasize its theoretical and methodological background, as well as J. Habermas's theory of communicative action.
\end{abstract}

Keywords: Health education, Unified Health System (UHS), Communicative action, Public health, Quality of life

\title{
Considerações iniciais
}

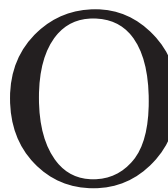

Movimento Sanitário brasileiro, em toda sua existência, tem tentado imprimir uma proposta de política de saúde centrada nas necessidades da população, buscando compreender os diferentes fatores que interferem na constituição do processo saúde-doença. No entanto, tem se deparado, ao longo desses anos, com contradições e conflitos inerentes a uma sociedade capitalista globalizada, onde as singularidades e especificidades parecem esvair-se em meio à complexidade de interesses sociais, políticos e econômicos atuantes. Nesse contexto, a cultura, as leis, as normas, o poder, as riquezas etc. são fatores que interagem cotidianamente, numa relação dialética, como forças de avanço e recuo dessa política.

Tal fato tem feito do Sistema Único de Saúde (SUS) - política de saúde implantada no Brasil a partir da Constituição Federal de 1988, mais precisamente pela Lei n. 8.080/90, com o objetivo de viabilizar os direitos de cidadania pelo Estado - uma política que, se por um lado vislumbra-se como uma proposta universal de garantia de direitos de cidadania, por outro tem sofrido as mazelas de um processo histórico, onde seu principal alvo - a população mais vulnerável econômica e socialmente - ainda caminha dissociada de um projeto que na prática a inclua como sujeito coparticipe de um processo que venha a contribuir para a promoção de sua saúde e qualidade de vida. Tal fato, associado à pouca tradição das instituições em gerenciamento público participativo, são fatores que têm dificultado para que o SUS avance rumo à efetivação de seus princípios e diretrizes. Esse movimento tem imposto limites à conformação e direcionalidade dessa política, o que de certa forma tem arranhado a 
dimensão objetiva e subjetiva dos seus princípios doutrinários, na medida em que as ações empreendidas ainda contabilizam um impacto insatisfatório no que se refere ao controle de agravos e à participação popular na prevenção de doenças, promoção da saúde e no controle social.

Esse aspecto pode ser visto como uma questão social que se objetiva pela inter-relação de fatores políticos, ideológicos, técnicos, sociais, culturais e organizacionais e concorrem para aumentar a distância entre população (sociedade civil) e gestão pública de saúde. Com isto, infere-se que o SUS, ao chegar à ponta, isto é, na base, a qual é constituída pelo núcleo familiar, tem esquecido que esta precisa ser tocada na sua dimensão de ser e saber, nos seus carecimentos, desejos e conhecimentos. É nessa dimensão que visualizamos a importância da influência da cultura organizacional e, consequentemente, a necessidade de se instituir propostas metodológicas que coloquem os diferentes sujeitos numa relação dialógica de construção de conhecimento, com vistas às transformações necessárias de suas realidades.

$\mathrm{Na}$ atualidade, o que se percebe é que as estratégias utilizadas (apesar da intenção) ainda não permitem um agir orientado para o entendimento do homem consigo, com o meio e seus problemas sociossanitários enfim, com seu projeto de vida. Por mais que se esforce e por mais que se faça, a saúde, em pleno século XXI, ainda não rompeu com o paradigma curativista, isto é, ainda é vista como resultado de um modelo, hospitalocêntrico e produto do avanço de tecnologias de apoio diagnóstico de média e alta complexidade, onde os sujeitos envolvidos perderam a direção da imagem objetivo que se pretende atingir - o homem como sujeito do seu processo de promoção da saúde, cura e reabilitação. Os "coletivos" de saúde pública, quer sejam de trabalhadores ou usuários, não se constituem ainda como efetivos instrumentos de avanço em direção às estratégias de promoção da saúde e prevenção de agravos, na medida em que não agregam às ações e serviços uma relação dialógica que promova a construção/ desconstrução/reconstrução de vivências, experiências, hábitos e costumes da população diante da realidade em que vivem. Isso sem falar que o controle social ainda deixa a desejar na medida em que os sujeitos não se colocam, de forma clara, como (co)partícipes de um processo de (re)estruturação de suas realidades sociossanitárias.

Esperamos muito da população, exigimos que ela "participe" das ações de saúde a exemplo das campanhas de vacinação e do controle de doenças, como 
a hanseníase, Aids, dengue, leishmaniose e tantas outras. Neste aspecto, as ações empreendidas trazem um caráter bastante pontual e fragmentado, tendo, como resultado, baixa efetividade nos seus resultados. Cometemos aí um grande equívoco; querermos que a participação da população se faça a "toque de caixa", simplesmente pelo querer institucional, onde o que está em jogo é o alcance de metas quantitativas, e não a capacidade de resposta que a população possa dar ao poder instituído diante de suas necessidades. Tal comportamento nos leva a (re)pensar a gestão pública nos seus pontos de fragilidade, e o maior deles tem sido a baixa capacidade em agregar valor popular às suas práticas, não por desconhecimento do seu marco legal instituinte, mas principalmente pelo despreparo em conduzir processos de trabalho que envolva os usuários.

Tal fato aponta para a busca de alternativas que coloquem esses saberes em um mesmo contexto, onde instituição e população passem a construir uma relação dialógica intermediada pela reflexão das vivências, dos conceitos que fundamentam a visão de mundo dos sujeitos, pela formulação de um diagnóstico situacional que evidencie forças, fraquezas e deixe claro os limites e as possibilidades de participação e mudanças.

Neste aspecto, há que se criar e/ou instituir processos pedagógicos de elaboração da visão de mundo dos sujeitos — que viabilize um processo de desconstrução/reconstrução dessa visão de mundo. É aí que reside a possibilidade de apropriação de conhecimento e de novas atitudes que podem levar à participação. Desta forma, o que se observa é que as ações de saúde ainda estão longe de desencadear um processo de mudança nos seus indicadores e nas suas metas, considerando que sempre estamos esperando da população usuária algo que ela ainda não tem condições de dar - a participação efetiva, consciente e propositiva. Isto significa que ao exigirmos a adesão da população aos projetos e propósitos institucionais, queimamos etapas de um processo educativo onde o que está em jogo é apenas a eficiência e a eficácia de um projeto técnico-institucional que não traduz a busca do diálogo de saberes entre instituição e população não promovendo, portanto, uma ação e reflexão em torno das questões sociais que afetam diretamente a sua estrutura de vida - como diz J. Habermas, o mundo da vida, em que vivem os sujeitos.

Segundo esse pensador, é no mundo da vida onde os processos comunicativos se dão, onde as relações subjetivas se constituem e se constroem, onde ocorrem as possibilidades de problematização da realidade, onde visões ingê- 
nuas e críticas se encontram e dão lugar a proposições coletivas, que ao serem materializadas ganham adesão dos sujeitos, pois já foram devidamente apropriadas por esses. Também é no mundo da vida onde os saberes e os conhecimentos adquiridos ao longo da trajetória de vida dos sujeitos - a linguagem e as formas de ser e estar no mundo - se evidenciam em um movimento dialético de desconstrução e reconstrução, ganhando direcionalidade e força.

Neste sentido, as ações que poderiam "tocar" o cidadão em sua dimensão subjetiva estão como que congeladas até que haja um despertar das organizações, dos profissionais e do sistema de saúde como um todo para uma nova dimensão de prática e, desta forma, estreitar o fosso que separa o Sistema Único de Saúde dos usuários. Assim entendido, há que se pensar na possibilidade de um caminho inverso no qual o sistema de saúde deve estar para a população tal como essa deve estar para o sistema de saúde, de forma organizada e participativa, opinando sobre as questões afetas às suas comunidades e na condução de suas soluções. Para tanto, esse (SUS) precisa abrir-se, chegar mais próximo dos sujeitos, suscitando um movimento baseado no agir-refletir-agir coletivamente que seja capaz de criar nos sujeitos uma condição crítica, avaliativa e propositiva dos processos por eles vivenciados.

É neste aspecto que J. Habermas (1983, p. 307) anuncia que "o mundo do sentido é aberto ao intérprete, somente na medida em que, ao mesmo tempo, problematiza seu próprio universo". Essa proposição coloca como condição a necessidade de se estabelecer uma relação dialógica — pautada por um agir comunicativo - onde os sujeitos passem a entender o mundo vivido por meio da prática de um discurso centrado nos aspectos significativos de suas vivências. Para isto, é necessário que as organizações de saúde pública estejam preparadas do ponto de vista pedagógico, de forma a construir e dinamizar uma racionalidade instrumental que seja capaz de impor um novo referencial no qual o homem esteja colocado como sujeito, munido de conhecimento crítico, capacidade teleológica e de objetivação, portanto com possibilidades de visualizar e pôr em prática o seu projeto de vida.

Neste sentido, vale lembrar que o próprio conceito de saúde, quer associado à teoria da causalidade (Leavel e Clark) ou como determinação social do processo saúde-doença (corrente latino-americana e canadense), só ganha sentido quando entendemos e colocamos o homem como sujeito vivo, pensante, comunicante, em todo processo de construção da política de saúde. Assim, o 
grande vilão desse processo passa a ser a instituição de saúde, na medida em que não propõe uma relação dialógica ente os sujeitos — profissionais de saúde e população.

Tal fato permite inferir a necessidade de se reduzir a distância pedagógica que ainda se estabelece entre o fazer organizacional e a população usuária dos serviços de saúde, entendendo que essa ainda é a maior desigualdade deflagrada no serviço de saúde hoje, na qual vivenciamos, cotidianamente, uma bipolaridade constante entre os que "sabem" e os que "não sabem", os que "pensam" e os que "não pensam", os "empoderados" e os "súditos".

Tomando por base as questões acima mencionadas, consideramos importante colocar para reflexão neste estudo o agir comunicativo como estratégia de redirecionamento das práticas de saúde, no momento em que se comemoram duas décadas de SUS na sociedade brasileira. Entendemos que nesse contexto é oportuno um repensar da direcionalidade dada às práticas sanitárias, às metodologias instituídas e às estratégias adotadas que tenham como objetivo favorecer a adesão e o compromisso da população com a política de saúde pública e, assim, contribuir para reorientação da política de saúde no Brasil.

As colocações aqui externadas encontram seu foco de análise nas ações de saúde e saneamento desenvolvidas no contexto do SUS no momento em que o Estado, por meio de suas instituições vem procurando desenvolver uma gestão por resultados, exigindo eficiência, eficácia e efetividade das ações empreendidas ${ }^{1}$. Ao identificarmos, através dos instrumentos utilizados para avaliar o desempenho institucional — os relatórios de gestão - é que verificamos que o alcance dos indicadores ainda se constitui no grande desafio. A avaliação nos mostra que pouco ou quase nada mudou nos indicadores de saúde, na forma de encaminhamento das questões coletivas pela comunidade, na forma como os processos de capacitação são desenvolvidos e, finalmente, no padrão da qualidade de vida da população usuária.

Além disso, em nossas pesquisas teóricas e analisando as práticas institucionais ao longo desses vinte anos de SUS, temos evidenciado a ausência de

1. Tal fato se evidencia mais claramente quando tais instituições sofrem processos de auditorias pelos órgãos de controle, como Tribunal de Contas da União - TCU, Controladoria Geral da União - CGU, ou quando são notificadas pelo Ministério Público. Em todos esses processos, são cobrados os resultados dos investimentos sociais de maneira mais contundente. 
um pensar e um fazer que coloque a população como centro do processo de racionalização das medidas a serem implantadas e/ou implementadas pelas organizações de saúde. Não obstante o exposto, vale ressaltar a possibilidade da existência de iniciativas isoladas e por vezes bem-sucedidas.

Neste sentido, pretendo abordar essa questão na perspectiva de evidenciar os caminhos que as práticas de saúde pública e mais especificamente as ações de educação em saúde pública continuam assumindo, buscando elementos críticos que norteiam esse agir e a partir daí focalizando as propostas pedagógicas que levem os indivíduos a participarem ativa e criticamente da construção da política de saúde do SUS e da sua cidadania.

\section{Um olhar sobre a história da ação educativa em saúde e as perspectivas do agir comunicativo em J. Habermas}

Muitos são os teóricos que vêm contribuindo com suas teses para um entendimento teórico-metodológico da ação educativa e comunicativa nos serviços de saúde desenvolvidos pelo Sistema Único de Saúde — SUS. Como exemplo, temos: Bordenave (1987) com ênfase nas estratégias de ensino-aprendizagem inserindo a problematização como eixo condutor desse processo; Freire $(1967,1970,1979)$ que em suas obras. Educação como prática para a liberdade, Pedagogia do oprimido e Educação e mudanças, coloca o homem como sujeito ativo de um processo em mudanças, sendo que para tanto propõe uma ação transformadora pautada na reflexão do saber e das vivências cotidianas; Valla e Stotz (1993), que trabalham a participação popular nos serviços de saúde e o controle social como exercício de cidadania e tantos outros valores que com seus estudos e pesquisas têm buscado refletir a ação educativa como eixo estruturante das ações de promoção e proteção à saúde do cidadão.

Não obstante as contribuições acima evidenciadas, trago para reflexão as contribuições de Jürgen Habermas sobre a sua teoria do agir comunicativo (1989). Neste aspecto, Habermas colabora na medida em que coloca a razão comunicativa como parte do mundo da vida, que é intermediada por símbolos que nascem a todo momento das interações e vivências entre os sujeitos e desses com as estruturas econômicas, políticas e organizativas onde se evidencia 
o poder e o saber centralizado - mundo do sistema. Essas relações que se estabelecem nesse contexto ganham espaço e valor na sociedade, se perpetuam em gerações por meio dos processos de comunicação. Este é o substrato básico para uma ação educativa em saúde.

Jürgen Habermas, sociólogo e filósofo alemão, têm seu nome atrelado à teoria crítica da Escola de Frankfurt, que ao lado de Adorno (1903-69), Marcuse (1898-1979), Horkeimer (1895-1973) e Benjamin (1892-1940) partilha os ideais da crítica radical à sociedade industrial moderna. Tal crítica encontra seu fundamento principal na racionalidade instrumental adotada pela sociedade moderna e pela necessidade de utilização de meios e/ou instrumentos para se chegar a determinado fim. A crítica a essa racionalidade recai no uso de tecnologias comunicativas, tradicionalmente comandadas por ideologias dominantes e regidas segundo os interesses do mundo dos sistemas. Nessa perspectiva, tais interesses penetram em diferentes segmentos sociais impulsionando uma ação de forma exógena, isto é, distantes de suas reais necessidades, gerando alienação e exclusão social do saber, do conhecimento e das possibilidades de apropriação de um projeto societário emancipador resultante de um pensar e de um fazer críticos.

Em sua teoria da ação comunicativa, Habermas, parte do princípio de que é através da linguagem que os homens se constituem em sujeitos de ação, estabelecendo um contexto de relações e interações sociais que desencadeiam os processos de mudança.

Chamo ação comunicativa àquela forma de interação social em que os planos de ação dos diversos atores ficam coordenados pelo intercâmbio de atos comunicativos, fazendo, para isso, uma utilização da linguagem (ou das correspondentes manifestações extra verbais) orientada ao entendimento. Na medida em que a comunicação serve ao entendimento (e não só ao exercício das influências recíprocas), pode adotar para as interações o papel de um mecanismo de coordenação da ação e com isso fazer possível a ação comunicativa (Habermas, 1987, p. 418)

A ação comunicativa, pensada desta forma, vem contribuir como fonte geradora de um processo de emancipação onde o homem, uma vez orientado a partir de um processo problematizador, seja capaz de formular uma concepção crítica de realidade e de construir não só a sua autonomia, mas também a auto- 
nomia dos diferentes coletivos a que pertence. Nesse movimento gesta-se a possibilidade de que, através da ação comunicativa, dialógica, este homem venha a libertar-se das amarras do poder constituído, fazendo de suas necessidades materiais uma ponte para o seu empoderamento. Neste sentido, o que se coloca em evidência é o conceito de razão preconizado por Habermas enquanto fundamento da linguagem expressa na relação dialógica entre os sujeitos. Assim, conforme coloca Pinent (1995, p. 37),

A conceituação de razão, o claro entendimento do que seja razão, para Habermas é de fundamental importância. Se em Kant a razão é subjetiva, inata, transcendental, e se em Popper ela é objetiva, em Habermas ela é comunicativa, dialógica. Se para o positivismo ela é a capacidade de manipular corretamente regras formais, para a ação comunicativa ela é a capacidade de dialogar seguindo a lógica do melhor argumento.

Ora, se estamos diante de um projeto humano, não podemos mergulhar numa relação unilateral e impessoal que dispense um olhar sobre os aspectos em torno dos quais a sociedade ergue sua história, onde os homens constroem o seu saber e o seu fazer - os quais não são desprovidos de sentido e desejo, pelo contrário, exigem cada vez mais uma dimensão interativa que não pode ser esvaziada pela racionalidade instrumental, pois, se assim for, a forma de pensar, sentir e agir do homem tende cada vez mais a se distanciar do coletivo, isto é, do seu princípio básico de sociabilidade. O que está em evidência é uma racionalidade comunicativa onde o homem, ao ser capaz de expressar suas vivências, percepções, expectativas, mostra-se capaz de mergulhar na sua condição de sujeito, interagindo por meio da utilização da linguagem, identificando-se enquanto grupo social, organizando-se socialmente, fazendo pactuações, construindo consensos, questionando as estruturas vigentes, sendo propositivo e fazendo o controle social em defesa de sua cidadania.

Com isto, estamos evidenciando uma perspectiva de existência de um individuo crítico, participativo, capaz de lutar pelos seus ideais e, como diz Karl Marx, "como lutador pela sua felicidade", enfim, como um ser capaz de promover sua própria inclusão social no contexto da sociedade - aqui representada pelo que Habermas chama de mundo da vida e mundo do sistema respectivamente. É importante notar que nesse movimento o indivíduo mantém uma relação dialética com ambas as dimensões de sociedade, de mundo, isto é, ora 
analisando, discutindo e problematizando, ora manifestando-se diante das estruturas sistêmicas, sendo "beneficiado" na condição de "usuário", "cliente" ou qualquer um desses adjetivos que o sistema o atribui.

Nesse movimento, (ele) é orientado a agir muitas vezes em defesa do próprio sistema, assim também coagido socialmente em suas possibilidades de organização e emancipação. A esse respeito, percebe-se, na literatura habermasiana uma disposição a uma crítica esclarecedora da sociedade contemporânea e de suas tecnologias em detrimento de uma racionalidade comunicativa que faça brotar um processo de consciência crítica da realidade, criando entre os sujeitos uma prontidão para a mudança que se objetivará mediante uma práxis emancipatória.

Diante do exposto, faz-se necessário trazer à vista uma identificação e reflexão sobre os métodos de ensino-aprendizagem instituídos, das possibilidades de proporcionarem um saber crítico e significativo junto aos diferentes coletivos, de suscitarem uma visão crítica dos sujeitos sobre as condições sociossanitárias em que vivem, bem como das suas possibilidades de emancipação. Neste aspecto, é importante buscar na rede do SUS um levantamento dessas práticas, de sua direcionalidade, metodologias e resultados.

\section{Ministério da Saúde/Fundação Nacional de Saúde, como referência de desenvolvimento de ação educativa em saúde}

Estudos teórico-metodológicos publicados sobre a ação educativa em saúde no Brasil ainda são raros. Pouco se tem avançado nesta direção, porém em um breve olhar sobre as publicações que norteiam essas práticas no contexto do SUS - e aqui vou referir à experiência do Ministério da Saúde que, desde a década de 1980, quando a então Divisão Nacional de Educação em Saúde - DNES observa-se um avanço significativo para a área por meio do incentivo às experiências de educação em saúde em todo o país, pautadas em metodologias alternativas que possibilitassem o desenvolvimento de uma consciência crítica onde a população passasse a ser protagonista dos processos de mudança de sua própria história sociossanitária. Neste sentido Geysa Mendonça, então diretora da DNES, no texto "Ação educativa e saúde: uma abordagem conceitual" já colocava que 
o maior desafio é criar, juntamente com a população, canais, métodos pelos quais ela vai se apropriando de conhecimentos e práticas importantes para a autonomia e seu desenvolvimento. O que nos parece mais honesto é que, através da rede de serviços básicos de saúde, se abra, com a população que é clientela da unidade de saúde, um diálogo sobre a história natural, real das doenças que mais a afligem, considerando na relação causa-efeito todas as variáveis que interferem no processo. (Mendonça, 1987, p. 11)

As colocações da autora, embora vendo a necessidade de uma abordagem focalizada no processo saúde-doença e seus condicionantes, abre uma perspectiva para a necessidade de metodologias que evidenciem práticas dialógicas entre os sujeitos no sentido de que se tornem capazes de, ao entender essa realidade, possam modificá-la. O que está em evidência, na fala da autora, é a perspectiva de desenvolvimento de uma consciência crítica dos sujeitos construídas por meio do diálogo entre iguais que seja capaz de envolver as pessoas: a) na reflexão sobre os aspectos de sua realidade (por exemplo, os problemas de saúde, habitação, produção etc.); b) na busca das causas desses problemas; c) no desenvolvimento de um plano de ação para solucionar os problemas identificados... Tal perspectiva encontra respaldo teórico-metodológico na pedagogia da problematização de Juan Diaz Bordenave (1987), que parte do princípio de que o desenvolvimento da consciência crítica dos cidadãos deve partir da problematização de sua realidade.

A pedagogia da problematização parte do princípio de que, num mundo em mudanças rápidas e profundas, o importante não são os conhecimentos ou ideias, nem os comportamentos corretos e fiéis ao esperado, senão o aumento da capacidade do aluno para detectar os problemas reais e buscar-lhes solução original e criativa. A experiência que deve ser valorizada é a observação grupal da própria realidade. O diálogo e a participação na ação transformadora das condições de vida. (Bordenave, 1987, p. 16)

$\mathrm{O}$ autor ainda ressalta como consequências possíveis dessa pedagogia um sujeito com perfil ativo, motivado, onde seu aprendizado deve está ligado aos aspectos significativos da realidade, cooperação, métodos e recursos adequados à realidade, tecnologias viáveis etnoculturalmente e resistência à dominação. Este é o enfoque que desde a década de 1980 vem norteando, teoricamente, as práticas educativas na saúde pública tanto no que diz respeito às ações diretas 
com a população como em relação aos processos de capacitação dos servidores de saúde para agirem no contexto do SUS.

A Fundação Nacional de Saúde - Funasa, órgão executivo do Ministério da Saúde nos estados para desenvolver ações de saneamento ambiental com vistas ao controle das endemias ocasionadas pela ausência de saneamento básico em municípios com até 50 mil habitantes, também adotou como eixo norteador de suas ações a abordagem pedagógica de Bordenave, tendo avançado na década de 1990 e início dos anos 2000 em direção a uma proposta sistematizada por meio da publicação Educação em saúde: diretrizes (Brasil, Fundação Nacional de Saúde, 2007). Nesse documento, a Funasa mostra a necessidade de construção sistemática de um projeto pedagógico que tenha por base a consolidação de diretrizes políticas e operacionais que apontam para a promoção da saúde e a melhoria da condição de vida da população. Tais diretrizes estão estruturadas a partir dos seguintes pilares:

- os fundamentos teóricos da educação;

- os princípios do Sistema Único de Saúde e o controle social;

- financiamento;

- convênios;

- estudos e pesquisas.

Nesse documento evidencia-se ainda a estruturação da educação em saúde na instituição como base sustentadora e orientadora de todo um processo de desenvolvimento das ações de saneamento ambiental, focada na missão institucional, isto é, como estratégia para o alcance das metas de inclusão social dos sujeitos. Neste sentido, a concepção de educação em saúde que se apresenta é de

Um processo sistemático, contínuo e permanente que objetiva a formação e o desenvolvimento da consciência crítica do cidadão, estimulando a busca de solução para os problemas vivenciados e a sua "participação real" no exercício do controle social. (Brasil 2007, p.17)

A educação em saúde, pensada dessa forma, traz implícito um componente básico de grande importância para o processo, que é a participação popular. Essa categoria se agrega ao produto da ação educativa como resultante de um processo pedagógico facilitador da elaboração da visão de mundo dos sujeitos 
- aqui chamado processo educativo. Nesse sentido, percebe-se que o conceito anunciado em ambas as instituições guarda uma sintonia com as colocações de J. Habermas ao trazer o diálogo como uma alternativa que motive a discussão e a construção de projetos que possam ser assumidos coletivamente.

A grande questão é saber como são produzidos esses processos. Que base metodológica vem sustentar o conceito de participação e educação. Observa-se, na literatura corrente, que vários são os instrumentais adotados pela instituição que favorece esse processo. Dentre esses destacamos as capacitações pedagógicas focadas na metodologia da problematização, tendo Bordenave (1987) como referência teórica, com o método do arco de Manguerez, como tentativa de evidenciar um processo de reflexão que parta da realidade de vida dos sujeitos, que leve à construção de hipóteses, à teorização, à definição coletiva de estratégias de ação e por fim a uma nova reflexão de realidade para uma nova ação. Ainda percebe-se no acervo documental da instituição publicações sobre o uso de recursos instrucionais como forma de facilitar o processo de ensino-aprendizagem. Assim, conforme coloca Bastos (2000, p. 14), ao enfocar a concepção de educador em saúde como "facilitador" da relação dialógica que se dá entre sujeitos, afirma:

Baseados nesse pensamento aplicamos as noções sobre recursos instrucionais das escolas em nossas vivências junto às comunidades e, sempre que possível, usamos materiais e linguagem da região, com alternativas populares e de menor custo, para que as pessoas percebam que não há nada de sofisticado e misterioso no que está apresentando. Aproveitar o saber do povo torna as comunidades mais confiantes em suas capacidades e potencialidades, e faz com que valorizem mais suas próprias alternativas de preservação e manutenção da saúde individual e coletiva.

Esses recursos enfatizados por Bastos, se colocados dentro da metodologia proposta, só terão sentidos enquanto instrumentos de intermediação da relação dialógica que se estabelece entre os sujeitos, isto é, como ponte para verificação, contestação e encaminhamento coletivos. Assim o uso do flip chart, retroprojetor, textos, cartaz etc. e de todo um conjunto de opções instrumentais oriundos das escolas formais, de modelos tradicionais ou contemporâneos, tem a efetividade de seu uso diretamente condicionado ao perfil sociocultural da população e aos mecanismos facilitadores da apropriação de conhecimentos, atitudes e hábitos. 
Também se evidencia no trabalho desenvolvido com a formação de conselheiros, cujo eixo norteador é o fortalecimento do controle social no SUS, essa preocupação com as metodologias utilizadas enquanto conjunto de instrumentos capazes de proporcionar mudanças nos indivíduos e no meio em que vivem. Neste sentido, evidenciamos que tal processo

traz como indicativo a utilização de metodologias que busquem a construção coletiva de conhecimentos, baseada na experiência de grupo, levando em consideração o conhecimento como prática concreta e real dos sujeitos a partir de suas vivências e histórias. Metodologias essas que ultrapassam as velhas formas autoritárias de lidar com a aprendizagem e muitas vezes utilizados como, por exemplo, a da comunicação unilateral, que transforma o indivíduo num mero receptor de teorias e conteúdos.

Recomenda-se, também a utilização de dinâmicas que propiciem um ambiente de troca de experiências, de reflexões pertinentes à atuação dos conselheiros de saúde e dos sujeitos sociais e de técnicas que favoreçam a sua participação e integração, como, por exemplo, reuniões de grupo, plenárias, estudos dirigidos, seminários, oficinas, todos envolvendo debates. (Brasil, 2006, p. 23)

Desta forma, percebe-se que embora o controle social para o SUS tenha sido alvo de projetos de capacitação, na prática tem avançado muito pouco, na medida em que não tem sido capaz de fazer do SUS um projeto de sociedade. Tudo isto deixa um grande vazio, tanto no contexto das práticas, quanto na população e na própria política de saúde. Diante disso, convém indagar: que efeitos essas práticas tidas como "emancipatórias" tem proporcionado ao controle social, e, consequentemente, na melhoria na qualidade de vida da população?

A participação popular é outra categoria que perpassa a ação educativa e é vista como uma ação que "busca promover a participação dos sujeitos, incentivando a reflexão, o diálogo e a expressão da afetividade, potencializando sua criatividade e sua autonomia" (Brasil, 2007, p. 18). O que se percebe é que desde a sua institucionalização, a ação educativa em saúde tem na relação dialógica seu ponto de partida e de chegada. Isto mostra uma tendência à utilização da teoria da ação comunicativa de Habermas diante dos processos educativos desenvolvidos.

É neste sentido que se indaga: qual a contribuição deste autor para a compreensão racional dos instrumentos utilizados nas práticas educativas em saúde? Por que então, diante das propostas teóricas existentes, que sem dúvida alguma 
tem potencial emancipador, não se obteve ainda como respostas a materialização de um projeto societário capaz de mudar o perfil das realidades sociossanitárias, uma vez que ainda persistem doenças e óbitos evitáveis? As ações de saneamento básico, como estratégia de política de saúde para melhoria dos indicadores de saúde e qualidade de vida da população, ainda não foram capazes de causar o impacto esperado nos indicadores de saúde e fazer com que a população se apropriasse dos serviços de saúde como seu.

\section{Conclusão}

Diante de tais indagações, precisamos rever e/ou buscar alternativas metodológicas que tragam para os espaços de reflexões (instituição $x$ comunidade) a forma de pensar, ser, agir e querer da população, bem como o contraponto de suas vivências com o sistema capitalista de produção, seus limites e possibilidades.

Precisamos buscar o caminho que leva à apropriação do conhecimento e à elevação da consciência crítica da população diante de seus problemas e carecimentos. Portanto, a hipótese que se levanta é a de que a teoria do agir comunicativo de Habermas constitui-se em uma ferramenta capaz de trazer à tona uma crítica esclarecedora dos métodos e técnicas utilizados pelo serviço de saúde (ação educativa) diante dos preceitos e das tecnologias estabelecidas pela sociedade contemporânea em detrimento de uma racionalidade comunicativa que faça emergir na população um processo de consciência crítica da realidade, criando entre os sujeitos uma identidade social e um sentimento de pertencimento dos serviços a eles destinados e, consequentemente, uma prontidão para a mudança.

Recebido em nov./2010 n Aprovado em mar./2011

\section{Referências biográicas}

ADORNO, T. W. Educação e emancipação. Rio de Janeiro: Paz e Terra, 1995.

BASTOS, Maria das Dores (Org.). Recursos Instrucionais para a Educação em Saúde. In: BRASIL. Fundação Nacional de Saúde. Recursos Instrucionais para Educação em Saúde. Goiânia, 2000. 
BORDENAVE, J. D. Opções pedagógicas. Ação participativa: capacitação de pessoal. Brasília: Centro de Documentação do Ministério da Saúde, 1987.

BRASIL. Ministério da Saúde. Conselho Nacional de Saúde. Diretrizes nacionais para o processo de Educação em Saúde. Brasília: Ed. do Ministério da Saúde, 2006.

. Fundação Nacional de Saúde. Diretrizes de educação em saúde visando a promoção da saúde: documento base. Brasília, 2007.

FREIRE, Paulo. Educação como prática da liberdade. Rio de Janeiro. Paz e Terra, 1967.

. Pedagogia do oprimido. Rio de Janeiro: Paz e Terra, 1970.

. Educação e mudança. Rio de Janeiro: Paz e Terra, 1979.

GIL, Antonio Carlos. Como elaborar projetos de pesquisa. 4. ed. São Paulo: Atlas, 2002 .

HABERMAS, Jürgen. Técnica e ciência como ideologia. São Paulo: Abril Cultural, 1975. p. 303-333. (Col. Os pensadores).

. Conhecimento e interesse. São Paulo: Abril Cultural, 1983. p. 301-312. (Col.

Os pensadores).

. Dialética e hermenêutica: para a crítica da hermenêutica de Gadamer. Tradução Álvaro L. M. Valls. Porto Alegre: L\&M, 1987.

. Consciência moral e agir comunicativo. Rio de Janeiro: Tempo Brasileiro, 1989.

. Teoria de la acción comunicativa. Madri: Cátedra, 1989.

. Ações, atos de fala, interações mediadas pela linguagem e mundo da vida. In:__ Pensamento pós-metafísico. Rio de Janeiro: Tempo Brasileiro, 1990.

MENDONÇA, Geysa de Freitas. Ação participativa: capacitação de pessoal. Brasília: Centro de Documentação do Ministério da Saúde, 1987.

PEDROSA, José Ivo; OLIVEIRA, Raimunda, Nonato da Cruz. O método da ação participativa em programas de educação em saúde: avaliação de uma experiência. Revista da Associação de Saúde Pública do Piauí - RASSP, v. 1, n. 1, p. 57-70, abr. 1998.

PINENT, Carlos Eduardo da Cunha. Situando Habermas. Educação, Porto Alegre, ano XVIII, n. 29, p. 31-40, 1995. 
SEVERINO, Antonio Joaquim. Metodologia do trabalho cientifico. 22. ed. rev. e ampl. de acordo com a ABNT. São Paulo: Cortez, 2002.

TESSER, Gelson João. Ação comunicativa de Habermas como um possível indicativo de reflexão para a inclusão social. Disponível em: $<$ http://www.cdr.unc.br $>$. Acesso em: 15 abr. 2009.

VALLA, Victor Vincente (Coord.). Participação popular e os serviços de saúde: o controle social como exercício de cidadania. Programa de Apoio à Reforma Sanitária. Fundação Oswaldo Cruz/Escola Nacional de Saúde Pública. Rio de Janeiro: Fiocruz, 1993.

VALLLA, Victor V.; STOTZ, Eduardo Navarro (Orgs.). Educação, saúde e cidadania. Petrópolis: Vozes, 1993.

VELASCO, Marina. Atos de fala e ações sociais: sobre a distinção entre locuções e perlocuções na teoria do agir comunicativo. Disponível em: <http://www.pdf4free. com>. Acesso em: 15 abr. 2009. 